\title{
Comorbidities of Allergic Rhinitis
}

\author{
Doo Hee Han and Chae-Seo Rhee \\ Department of Otorhinolaryngology, \\ Seoul National University College of Medicine, Seoul, \\ Korea
}

\section{Introduction}

Allergic rhinitis (AR) is a symptomatic nose disorder induced after exposure to allergens via IgE-mediated hypersensitivity reactions, which are characterized by 4 cardinal symptoms: nasal obstruction, watery rhinorrhea, nasal itching and sneezing. For both children and adults, AR is more than just sneezing and nose itching. Complications of this disease are numerous and can have a significant impact, both physically and psychosocially. Major comorbidities in patients with AR include asthma, rhinosinusitis (RS), otitis media with effusion (OME), and sleep disturbance. The symptoms of AR can cause not only physical problems to the nose and lower airway, but also psychosocial problems including those in learning and cognitive processes and in missing work or school (Fig. 1). Thus, it is very important to understand other conditions caused by AR when managing this disorder.

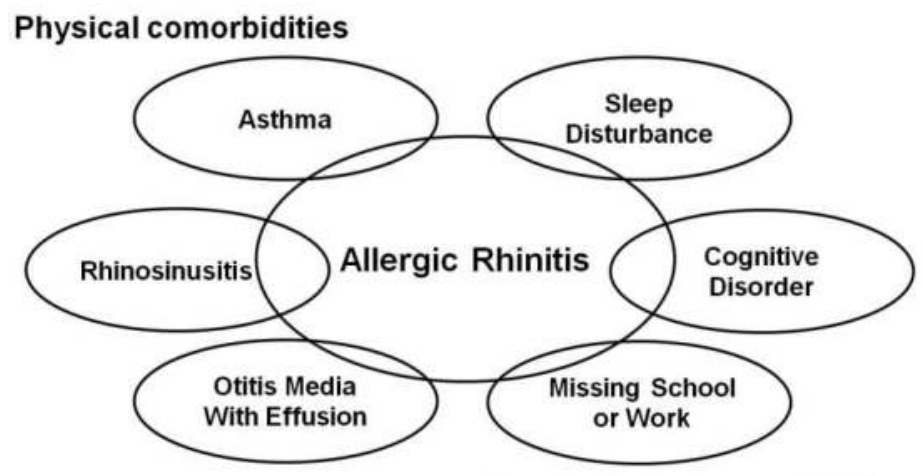

Psychological comorbidities

Fig. 1. Physical and psychological comorbidities of AR (Adapted from Spector, 1997)

The ongoing efforts of physicians to identify comorbidities of AR in the fields of allergy can be put to practical use in caring and protecting the community from the burden of disease as well as saving costs and offering preventive education. Moreover, providing information to the patients with AR is expected to have a direct and positive effect on their well being. In this chapter, we will provide an overview of the comorbidities of AR that could cause both physical and psychosocial complications. 


\section{Physical comorbidities}

\subsection{AR and asthma}

$\mathrm{AR}$ and asthma affect the upper and lower respiratory tract, respectively. Both are characterized by inflammation of the respiratory mucosa and involve similar inflammatory cells and mediators. Moreover AR and asthma have a considerable impact on quality of life, work and school productive, absenteeism, and individual and socioeconomic burden (Gaugris et al., 2006; Bachert et al., 2002; Bousquet et al., 2001). The socioeconomic burden via annual costs of treating $\mathrm{AR}$ and asthma, both direct costs such as hospitalization, medication and indirect costs such as time lost from work are substantial, and represent heavier burden in modern societies.

\subsubsection{Association between AR and asthma}

$\mathrm{AR}$ and asthma commonly coexist. Among asthmatic patients, approximately $85 \%$ also have AR. Conversely, up to $40 \%$ of AR patients have or will develop asthma (Bousquet et al., 2001; Guerra et al., 2002). There are many common anatomical and pathophysiological features between upper and lower airway disorders, primarily in histology and immunology. Examples of common anatomical features include ciliated columnar epithelial cells, mucinous glands, vasculature, and innervation (Baraniuk, 1997). Both AR and asthma are chronic inflammatory diseases of the upper and lower airways and their inflammatory mechanisms are characterized by inflammatory infiltrates made up of eosinophils, $\mathrm{T}$ cells, and mast cells that release several mediators, chemokines and cytokines, inducing local and systemic IgE synthesis, and activate a systemic link via the bone marrow.

AR has been shown to be a risk factor for asthma in children and adults (Leynaert et al., 2000). A longitudinal, population-based study confirmed an association between AR and adult-onset asthma (Shaaban et al., 2008). In another study, among 1,836 college freshman, those with AR were significantly more likely to have asthma by the 23 -year follow-up than those without (Settipane et al., 1994).

In $\mathrm{AR}$, one distinction is heavy vascularization of the nasal passages, which may lead to severe nasal obstruction. In asthma, the presence of smooth muscle from the trachea to the bronchioles can result in characteristic bronchoconstriction. Despite these differences, similarities exist. Notably, the anatomical structure and physiology of the airway mucosa are similar in both upper and lower airway (Bousquet et al., 2003).

Inflammation is a central component of both conditions. In AR, the inflammatory cascade is initiated by allergen deposition on the nasal mucosa and comprises early-phase and often late-phase responses. The antigen cross-links and activates IgE receptors, resulting in the degranulation of mast cells and the release of several mediators of inflammation, including histamine, prostaglandins, leukotrienes, and proteases, leading to sneezing, itching, rhinorrhea and congestion symptoms of AR. In asthma, antigen cross-linking and activation of IgE receptors may precipitate acute airway constriction.

AR may promote or exacerbate asthma through several physiological mechanisms that link 2 disorders. An early study investigating the integrated airway hypothesis suggested a nasobronchial reflex arc as a potential mechanism linking upper and lower airway disorders (Kaufman et al., 1970). Based on this hypothesis, nasal allergen challenge affects bronchial hyperresponsiveness through a reflex arc that involves trigeminal afferents and vagal efferents. In addition, other mechanisms include systemic release of mediators and cytokines, postnasal drip resulting irritation and oral breathing caused by nasal obstruction, 
which causes dry, cold air to penetrate into the bronchi and promote bronchial hyperresponsiveness (Meltzer, 2005) (Fig. 2).

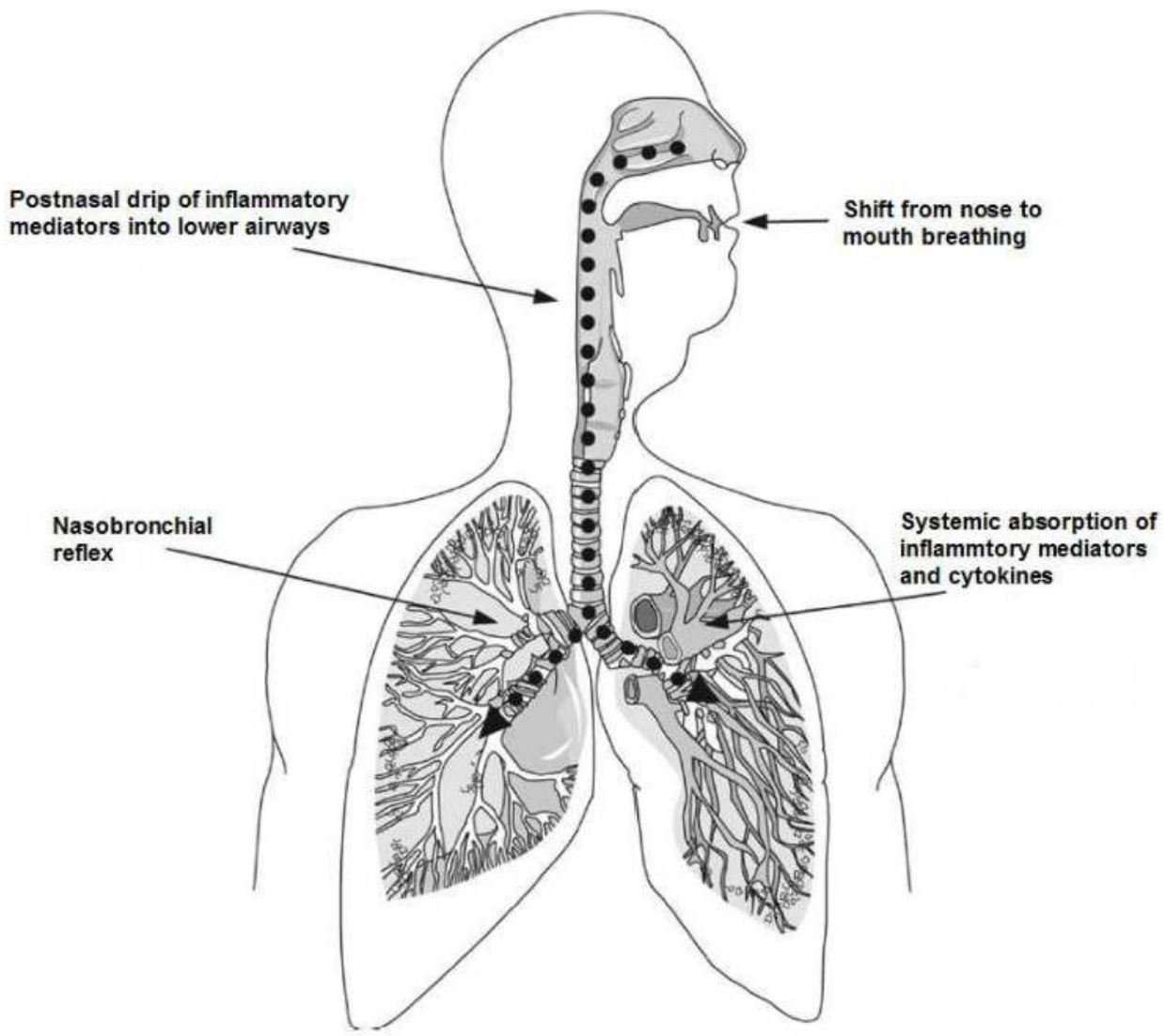

Fig. 2. Mechanisms of pathologic relationships between upper and lower airways (Adapted from Meltzer, 2005).

\subsubsection{Asthma evaluation in AR}

Allergic Rhinitis and its Impact on Asthma (ARIA) guidelines recommend that asthma patients be evaluated for AR and, conversely, that AR patients be evaluated for asthma (Bousquet et al., 2001). In a prospective study evaluating 375 adults with persistent moderate to severe AR and 115 controls, the authors concluded that patients with persistent moderate to severe AR without an asthma diagnosis should be evaluated for the lower airway with pulmonary function testing (Ciprandi et al., 2008). Similarly, ARIA 2008 updates recommend that persistent AR patients should be evaluated for asthma (Bousquet et al., 2008). In our previous study, 173 AR patients were evaluated for the lower airway with the methacholine bronchoprovocation test and we recommend lower airway evaluation for the selected patients with nasal polyps, moderate to severe symptoms, and high blood eosinophil count $(>320$ cells $/ \mu \mathrm{L})$ instead of a routine lower airway evaluation 
(Ahn et al., 2010). In another study, persistent type of rhinitis and parental history of asthma were significant and independent risk factors for bronchial hyperresponsiveness in AR children (Choi et al., 2007).

\subsubsection{Treatment of AR}

Early, active treatment of AR may be appropriate to decrease the incidence and morbidity associated with asthma. In a retrospective US cohort study of medical records covering 1 year for 4,944 asthmatic patients, approximately $73 \%$ were treated for AR. Asthma-related events occurred more often in untreated patients than in treated patients (6.6\% vs. $1.3 \%)$ (Crystal-Peters et al., 2002).

Controlling nasal symptoms with intranasal steroids improves asthma symptoms and nonspecific bronchial hyperresponsiveness (Watson et al., 1993). The authors reported that bronchial hyperresponsiveness to methacholine was significantly reduced in patients with perennial AR and asthma following treatment with intranasal steroids but not following intranasal placebo. More importantly, they also performed a radiolabeled deposition study of intranasal steroid administration and found that less than $2 \%$ was deposited in the chest area. These results suggest that treatment of inflammation in the upper airways indirectly improves asthma symptoms and decreases bronchial hyperresponsiveness, which is not a direct effect of the intranasally administered corticosteroid on the lower airways (Watson et al., 1993).

A 3-year retrospective cohort study conducted in 14 US centers evaluated whether treatment with intranasal corticosteroid (INS) in patients of 5 years or older with asthma was associated with a reduced risk of emergency room visits for asthma (Adams et al., 2002). Treatment of nasal conditions, particularly with INSs, appeared to prevent asthma exacerbations leading to emergency room visits.

\subsection{AR and RS}

$\mathrm{AR}$ and RS are increasingly being regarded as interrelated and part of a spectrum of upper airway inflammatory disease. AR also may be a contributing factor in $25 \%$ to $30 \%$ of patients with acute maxillary sinusitis and in as many as $60 \%$ to $80 \%$ of patients with chronic sinusitis (Spector, 1997). At the least, AR is associated with and probably a predisposing factor in the development of RS (Slavin, 1998). Both conditions are characterized by an inflammatory response leading to an altered milieu within the nose and paranasal sinuses, thus rendering normal host defenses weakened and susceptible to further inflammatory insult.

However, the role of allergy in the pathogenesis of RS has been under debate and controversy over the past several years.

\subsubsection{Association between AR and RS}

RS is an inflammation of the nose and paranasal sinuses, attributed to many potential factors. The term "rhinosinusitis" rather than "sinusitis" reflects more accurately close anatomical and pathophysiological relationship between rhinitis and chronic sinusitis, which are commonly comorbid. The typical pathophysiological scheme leading to the development of RS starts with some inciting agents (viral, bacterial, fungal, allergen) or predisposing factor (anatomical, immunological) leading to generalized mucosal edema and inflammation. In the development of RS, mucosal inflammation leads to ciliary dysfunction 
and mucus stasis, as well as edema of the sinus ostia. The stasis of secretions within the sinuses serves as a nidus for bacterial colonization and growth. These events coupled with the impairment of host defenses as a result of the inflammatory mediators released in response to the inciting agent, create a cycle of sustained inflammation that can chronically damage the nasal and paranasal sinus linings (Ahmad and Zacharek, 2008; Gwaltney et al., 1995) (Fig. 3).

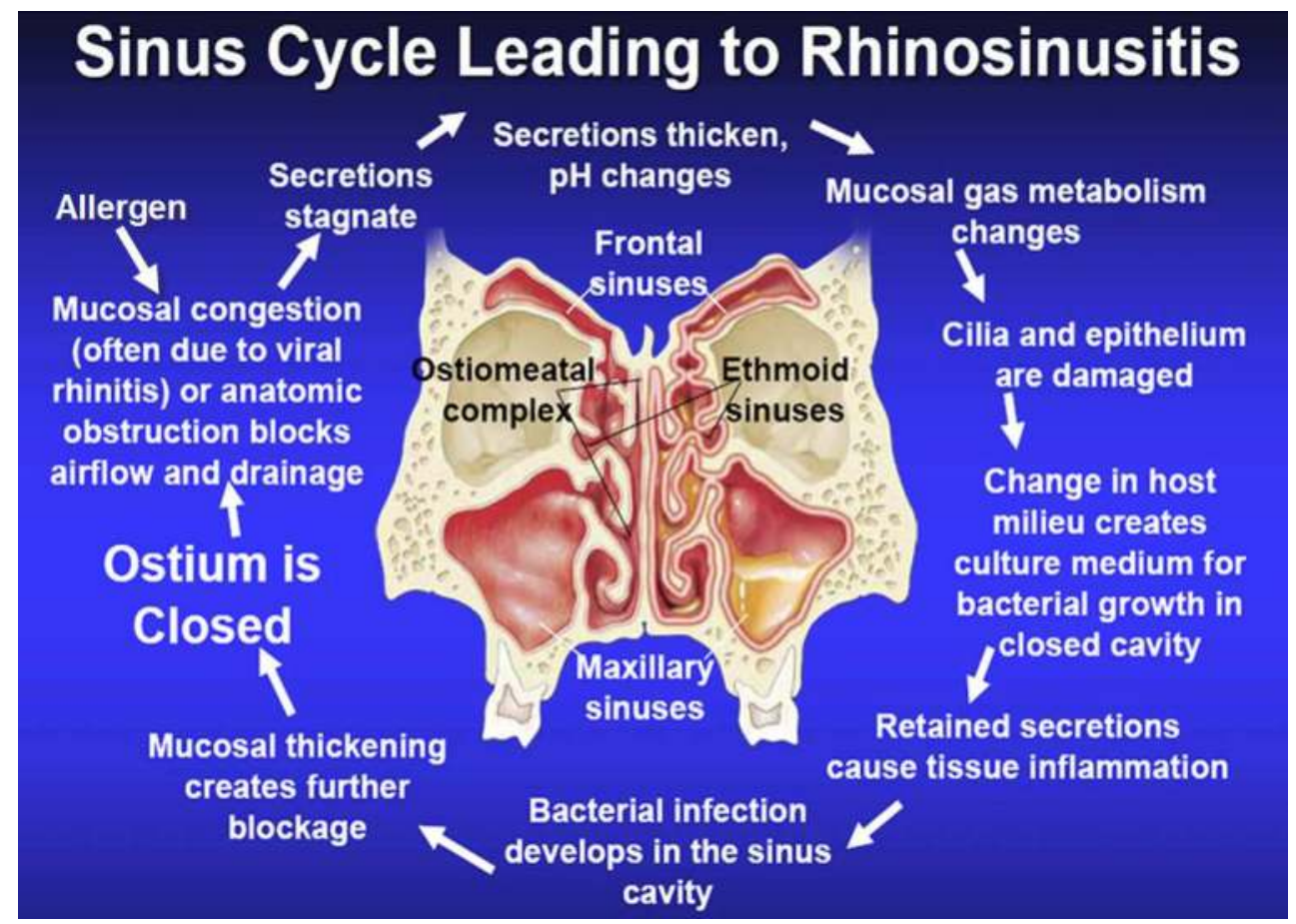

Fig. 3. Sinus cycle leading to RS (Adapted from Ahmad and Zacharek, 2008)

Adult chronic RS was defined as a group of disorders characterized by inflammation of the mucosa of the nose and paranasal sinuses of at least 12 weeks duration. In the past, chronic RS was characterized as a disease process caused by an anatomical obstruction of the sinus ostia, specifically ostiomeatal complex occlusion. The factors leading to this obstruction included viral infection aided by anatomical factors, leading to mucosal inflammation and edema, with thickening of mucus secretions and secondary bacterial infection. It has become clear that the pathogenic mechanisms are more complex than would be explained by a simple model and that there are other chronic inflammatory processes that contribute to the development of chronic RS. However, the exact mechanism by which allergy predisposes to the development of chronic RS has not been fully elucidated.

According to another model of the pathogenesis of RS, chronic RS is characterized by basement membrane thickening, subepithelial fibrosis and edema, goblet cell hyperplasia, and persistent inflammation (Christodoulopoulos et al., 2000). Like in asthma, remodeling of the mucosa occurs in response to this chronic and progressive inflammation. This model of 
pathogenesis also supports the notion of a unified airway with similar histopathological changes and immunological mechanism occurring as a result of inflammatory insult.

In a 1989 study, skin testing in 2 groups of young adults, one with acute maxillary sinusitis, and a matched group without sinusitis, revealed that the prevalence of positive allergen testing was greater in the group with RS (45\% vs. 33\%) (Savolainen, 1989). The author thus concluded that allergy did play a role in the development of acute RS, and that it was more common among atopic individuals. In another study, positive inhalant allergy testing was present in over $50 \%$ of the 120 patients undergoing endoscopic sinus surgery, which led him to conclude that allergy may be a predisposing cause of chronic sinusitis (Kennedy, 1992).

The contribution of allergy in the pathophysiology of both acute and chronic RS has been supported by studies examining the role of the ethmoid sinuses in terms of immunological, histopathological and postsurgical changes. The ethmoid mucosa affected by RS demonstrates an increased CD4/CD8 ratio and increase in the number of eosinophils and mast cells as well as extracellular matrix deposition, basement membrane disruption, and denudation of the epithelium (Christodoulopoulos et al., 2000). These findings are similar to the effect of allergy on other parts of the respiratory tract. In another study attempting to correlate tissue histopathology in chronic RS with immune mechanisms in allergic disease, the conclusions were that the proposed method for quantifying tissue eosinophilia in sinus mucosa was reliable and valid and that a relatively strong correlation existed between CT scan stage and tissue eosinophilia in chronic RS (Bhattacharyya et al., 2001).

Several studies examining the relationship between allergen exposure or provocation and RS exacerbation have also suggested a common mechanism in AR and RS (Pelikan and Pelikan-Filipek, 1990; Conner et al., 1989; Slavin, 1998). The investigators demonstrated an increase in metabolic activity of the maxillary sinus mucosa in chronic RS patients during ragweed season, using single-photon emission CT scanning (Slavin, 1998).

Evidence of a common pathophysiological mechanism between AR and RS is convincing. Although a clear causal mechanism leading from AR to the development of RS remains to be elucidated, an increasing number of studies have found the possibility and evidence of this link.

\subsection{AR and OME}

OME is one of the most commonly encountered diseases in children, affecting approximately $90 \%$ of children at some time before school age (Tos, 1984). OME is characterized by an accumulation of fluid in the middle ear behind an intact tympanic membrane in the absence of signs and symptoms of acute infection. If we look at the natural history of OME, many cases are self-limited and resolve spontaneously (Williamson et al., 1994). But, OME is the most frequent cause of hearing loss in children (Thomas et al., 2006; Shekelle et al., 2002).

An epidemiologic link between OME and AR has been demonstrated in many trials (Alles et al., 2001; Tomonaga et al., 1988). Prevalence of AR among patients with chronic or recurrent $\mathrm{OME}$ is higher than that seen in the same age group in the general population.

\subsubsection{Pathophysiology of OME and AR}

The etiology of OME is multifactorial. It may be related to bacterial infection, poor clearance due to Eustachian tube (E-tube) dysfunction, local inflammatory reactions and possibly atopy (Thomas et al., 2006; Luong and Roland, 2008). 
Data from several animal studies have suggested a link between nasal allergic inflammation and E-tube dysfunction. For example, an intranasal pollen antigen challenge significantly compromised E-tube function in 23 passively sensitized juvenile rhesus monkeys (Doyle et al., 1984). A nasal allergen challenge in rats resulted in E-tube inflammation, negative pressure and hindrance of mucociliary clearance (Ebert et al., 2007). Another previous study showed negative middle ear pressure following nasal allergen challenge in subjects with AR and hypothesized the involvement of both immunological and mechanical mechanisms (O'Connor et al., 1984). E-tube dysfunction developed during allergy season in $60 \%$ of children with seasonal AR and correlated with AR symptom severity (Osur et al., 1989).

Because the E-tube lining is contiguous with the nasopharynx, allergic disorders such as AR may cause inflammation and swelling in this region resulting in E-tube obstruction in the same manner as in the nasal mucosa (Alles et al., 2001; Luong and Roland, 2008; Fireman, 1988) (Fig. 4). Furthermore, it has been found that a reduction in the size of the lumen in an inflamed E-tube could impede mucociliary function, thus delaying clearance of acute infective middle ear effusion, leading to recurrent OME (Alles et al., 2001).

Several studies analyzing middle ear mucosa and effusions in atopic patients with OME have demonstrated that the composition of the inflammatory substrate in acute otitis media is similar to the type I late-phase allergic response seen in other areas of the respiratory tract, such as in AR, chronic RS, and asthma (Nguyen et al., 2004; Sobol et al., 2002; Hurst, 1996). The middle ear effusions of atopic patients with OME showed significantly higher levels of eosinophils, T lymphocytes, and IL-4 mRNA+ cells $(\mathrm{p}<0.01)$ and significantly lower levels of neutrophils and IFN- $\gamma$ mRNA+ cells $(\mathrm{p}<0.01)$ compared to non-atopic patients with OME (Nguyen et al., 2004). Similarly, in another study, a higher percentage of eosinophils and T lymphocytes, and a higher percentage of cells expressing IL-4 and IL-5 were found among atopic patients with OME (Sobol et al., 2002).

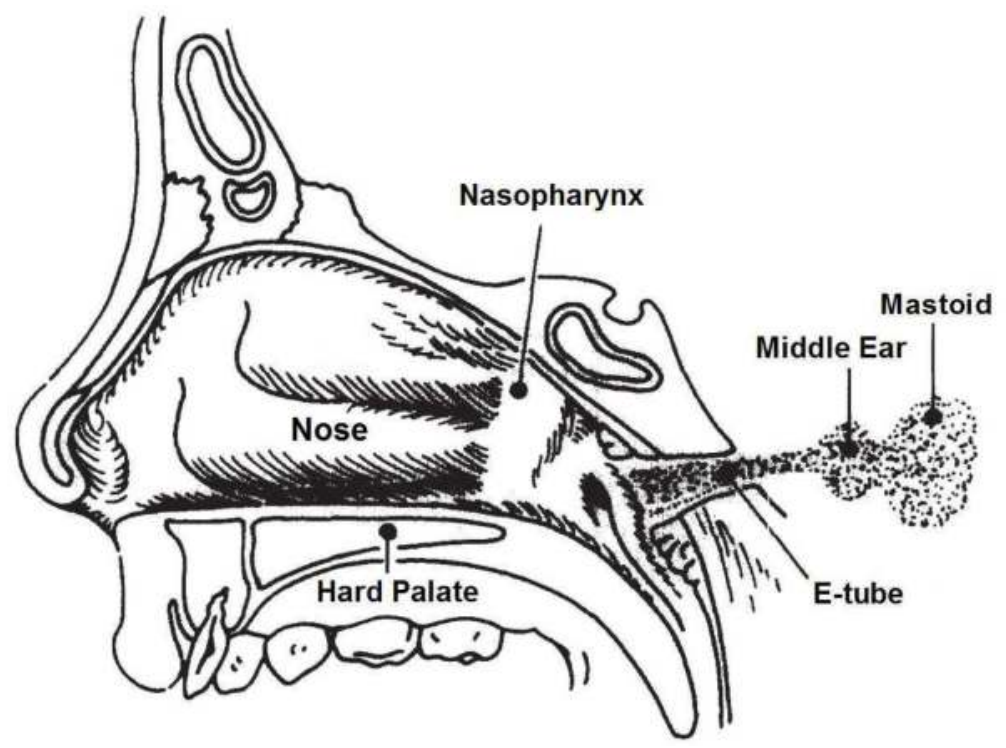

Fig. 4. Schematic diagram showing anatomical relationship of E-tube between the nasopharynx and middle ear (Adapted from Fireman, 1988) 


\subsubsection{Treatment of OME}

Because of the pathophysiological associations of AR with OME, treatments focusing on allergic inflammation may be helpful in the management of OME (Caffarelli et al., 1998; Fireman, 1988).

A meta-analysis of 16 randomized controlled trials demonstrated no significant benefit from antihistamines, decongestants, or combined antihistamines and decongestants versus placebo for treatment of OME (Griffin et al., 2006). However, in a meta-analysis of 6 randomized clinical trials, oral steroids administered for 7-14 days increased the rate of complete effusion resolution versus no steroid (Rosenfeld et al., 1991). A Cochrane database review yielded very similar results, demonstrating a quicker resolution of OME in the short term $(\leq 2 \mathrm{wk})$ with oral steroids alone or in combination with antibiotics (Thomas et al., 2006). However, there are likely to be safety concerns surrounding oral corticosteroids, such as behavioral changes, increased appetite, weight gain, and adrenal and growth suppression. On the contrary, INS has limited systemic absorption, these drugs offer safety advantages over oral corticosteroids and would be expected to exert their anti-inflammatory effects more locally in the nose, nasopharynx, and E-tube (Tracy et al., 1998). In this study, the authors compared the effects of prophylactic antibiotic alone or in combination with either intranasal beclomethasone or placebo on middle ear pressure, otoscopic examination, and symptom scores in 61 children with persistent middle ear effusion greater than 3 months. Subjects with the beclomethasone plus antibiotic group improved more rapidly in middle ear pressure and otoscopic examination than those with the antibiotic alone or placebo groups during the initial $8 \mathrm{wk}$. At $12 \mathrm{wk}$, only the combination treatment showed significant improvement in bilateral ear pressures. In addition, symptom resolution was significantly greater at $12 \mathrm{wk}$ with antibiotic plus beclomethasone group than with the antibiotic alone group. However, there were no differences in outcomes between atopic and nonatopic subjects (Tracy et al., 1998). In another previous study, patients with OME treated with mometasone furoate nasal spray experienced significantly higher rates of resolution of OME at 6 wk compared with untreated controls $(42.2 \%$ vs. $14.5 \% ; \mathrm{p}<0.001)$ (Cengel and Akyol, 2006).

In conclusion, atopic status should be evaluated in recurrent or chronic OME patients who had no response to antibiotic therapy and INS could be used as an adjunct to treatment of OME patients with AR. However, further studies are needed to elucidate whether atopic status or rhinitis itself may influence the development of OME.

\subsection{AR and sleep disturbance}

The effect of AR on sleep can impair a patient's quality of life (Canonica et al., 2007; Schatz, 2007). A nationwide controlled cross-sectional study showed that patients with AR have more difficulties in falling asleep, take more sleeping drugs, suffer from nocturnal awakenings, and feel that they do not get sufficient sleep when compared to healthy controls (Leger et al., 2006). Children with AR can experience micro-arousal during their sleep and irregular breathing.

A prospective study of 39 children with habitual snoring revealed that 14 subjects (36\%) showed sensitivity to allergens (McColley et al., 1997), which is higher than expected for the general pediatric population. Based on subjective criteria, sleep apnea syndrome has also been found to be more prevalent in AR than in controls (Leger et al., 2006). The reasons for poor sleep in AR are not clearly understood, but may be related, at least in part, to nasal congestion (Meltzer, 2004). Several studies have shown the relationships between AR and 
nasal obstruction and abnormal breathing during sleep, snoring and sleep apnea (Scharf and Cohen, 1998; Young et al., 1997).

The impact of the severity of rhinitis on quality of life including sleep, daily activities, and work performance was shown to be stronger than the duration of rhinitis (Bousquet et al., 2006). Another study showed that the severity of rhinitis, but not its frequency, was significant factors for severe insomnia, hypersomnia, respiratory arrest, apnea, sleepiness, and regular use of sedatives (Leger et al., 2006). Recently, we are conducting multi-center cohort study on the complication of rhinitis in Korean children. All patients were classified into 4 categories (intermittent mild, intermittent moderate to severe, persistent mild and persistent moderate to severe) using ARIA classification, and Korean version of Obstructive Sleep Apnea 18 (KOSA18) questionnaire were performed. High KOSA-18 scores mean more sleep disturbance. In our cohort study, the preliminary results $(n=999)$ showed that sleep disturbance was more frequent according to the ARIA classification (Fig. 5) and there were no differences between atopic and nonatopic patients $(48.7 \pm 17.5$ vs. $51.1 \pm 19.7, \mathrm{p}=0.120)$ (unpublished data).

In these groups, after the treatment of rhinitis, KOSA-18 scores at 6 months were lower than those of baseline; sleep disturbance were improved after the 6-month follow-up (Fig. 6).

AR appears to increase the risk of obstructive sleep apnea syndrome (OSAS) in children. Adequate treatment of AR can reduce the severity of OSAS and prevent the emergence of an elongated face, which predisposes patients to OSAS. It may also reduce the severity of coexisting OSAS.

\section{Psychosocial comorbidities}

\subsection{AR and cognitive disorder}

AR leads to psychosocial complications such as cognitive impairment and learning problems as well as physical complications. Young people, with and without treatment, were given the task, during the ongoing pollen season, to learn about agriculture in desert environments. The results showed that individuals receiving placebo or sedative antihistamines performed significantly worse than healthy controls (Vuurman et al., 1993). In another study, patients allergic to ragweed have impaired cognitive learning during the pollen season and some also had memory impairment (Marshall et al., 2000). It was also shown that patients with AR symptoms take a longer time to make decisions and have a slower psychomotor rate than healthy control subjects.

However, it is under debate whether AR itself does or does not lead to learning problems among allergic students. Resultant symptoms, such as sleep deprivation and general malaise can affect concentration and learning. Consequently, this theory argues that cognitive difficulties are a secondary result of sleep problems.

The consequences of $\mathrm{AR}$ effect on learning and other cognitive functions in relation to school performance have been established. A case-control study was conducted on 1,834 students sitting for the national examinations in mathematics, English and science (Walker et al., 2007). Those who had allergic symptoms during the examination period had a $40 \%$ higher risk of achieving lower grades than students who did not have symptoms.

Children with AR may fall behind in classes. Sniffling, rubbing and blowing the nose are more common among children with AR than those without. These behaviors make children self-conscious and peers may be annoyed by them, leading to teasing and a further increase in their stress levels (Meltzer, 2001) and may cause behavioral disorders. Thus, adequate treatment of AR should be needed, especially in school children. 
Total patients

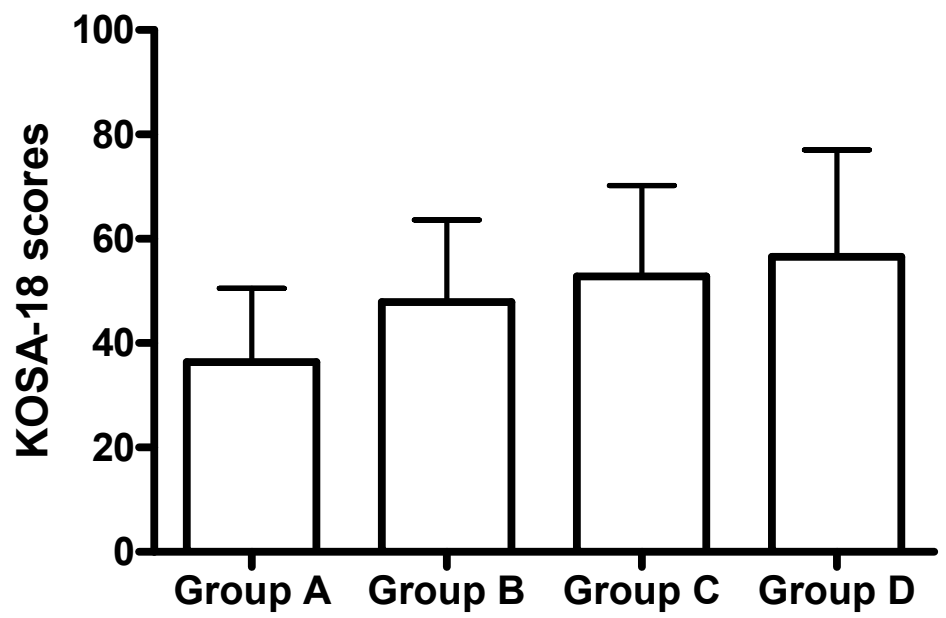

(a) Total patients

\section{AR/NAR patients}

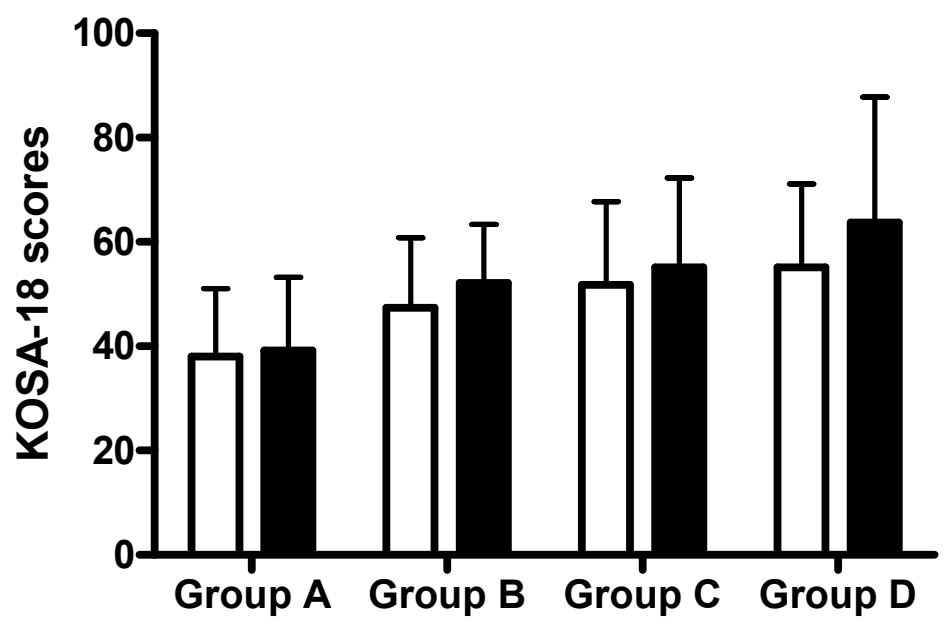

(b) AR/NAR patients

Fig. 5. Mean differences of KOSA-18 scores according to ARIA classification among (a) total patients and (b) allergic rhinitis (AR)/non allergic rhinitis (NAR) patients. All the data showed statistical significances ( $p<0.001$, adjusted to age). Group A: intermittent mild, Group B: intermittent moderate to severe, Group C: persistent mild, Group D: persistent moderate to severe. $\square$ : AR patients, $\mathbf{~ : ~ N A R ~ p a t i e n t s ~}$ 


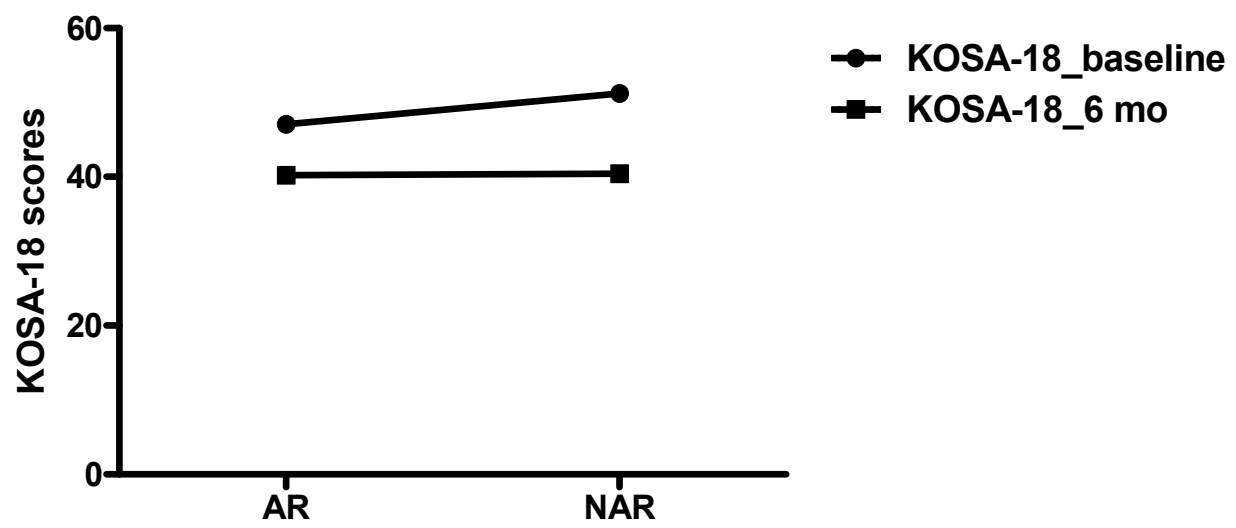

(a) KOSA-18 scores changes between AR/NAR patients

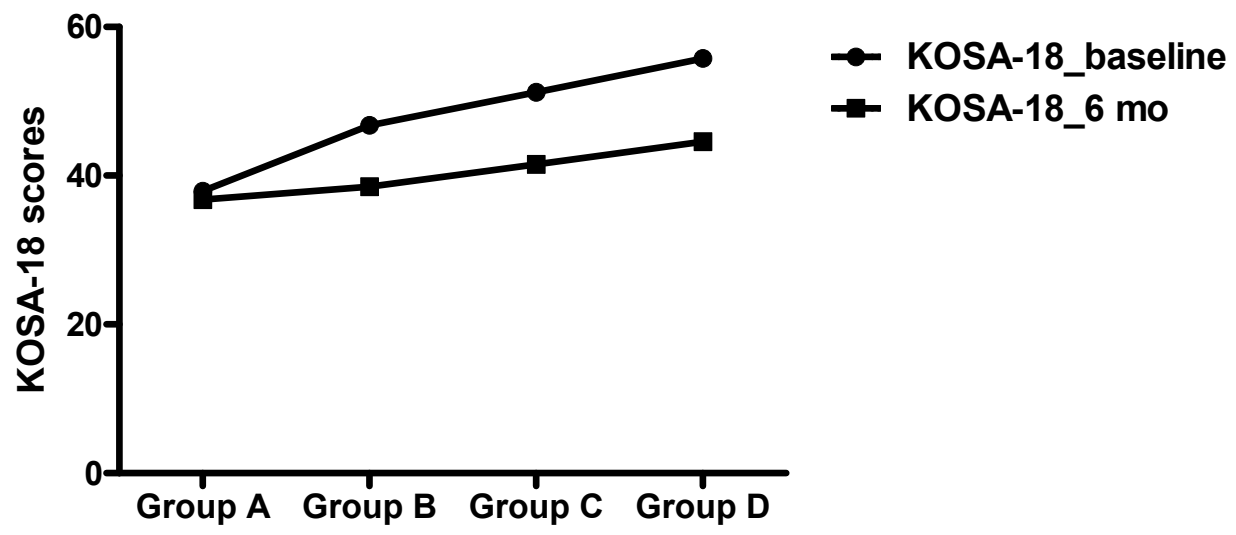

(b) KOSA-18 scores changes according to ARIA classification

Fig. 6. Mean differences of KOSA-18 scores after the treatment of rhinitis (a) between AR/NAR patients and (b) according to ARIA classification. Group A: intermittent mild, Group B: intermittent moderate to severe, Group C: persistent mild, Group D: persistent moderate to severe. 


\subsection{AR and missing school or work}

AR has considerable negative effects on both school-aged children and adult workers. Especially in school-aged children, it can not only affect sleep and cognitive function, but also cause school absenteeism and presenteeism. Untreated AR in childhood could cause sleep disturbances and daytime sleepiness, absenteeism and presenteeism (inattention, distraction, lack of concentration), irritability and mood disorders (Jauregui et al., 2009). In terms of adult workers, a previous study in the US evaluated economic impact of workplace productivity losses due to AR (Lamb et al., 2006). A total of 8,267 US employees at 47 employer locations volunteered to participate in health/wellness screenings. AR was the most prevalent; $55 \%$ of employees reported AR symptoms for an average of 52.5 days, were absent 3.6 days per year. The mean total productivity losses (absenteeism+presenteeism) were 593 US dollars for AR, 518 dollars for high stress, 277 dollars for migraine, 273 dollars for depression, 269 dollars for arthritis/rheumatism, 248 dollars for anxiety disorder, 181 dollars for respiratory infections, 105 dollars for hypertension, 95 dollars for diabetes, 85 dollars for asthma, and 40 dollars for coronary heart disease. Thus, the authors suggested that allergies are major contributors to the total cost of health-related absenteeism and presenteeism.

\section{Conclusion}

AR has a considerable effect on one's quality of life and can have significant consequences if left untreated. The consequences are more far-reaching than expected. Because all the possible comorbidities of AR have significant consequences to the community, it is fair to say that physicians and patients should pay close attention to prevent the occurrence of comorbidities. Furthermore, the adequate treatment of AR could prevent physical and psychosocial complications.

\section{References}

Adams RJ, Fuhlbrigge AL, Finkelstein JA, Weiss ST. Intranasal steroids and the risk of emergency department visits for asthma. J Allergy Clin Immunol 2002;109:636-42.

Ahmad N, Zacharek MA. Allergic rhinitis and rhinosinusitis. Otolaryngol Clin North Am 2008;41:267-81, v.

Ahn Y, An SY, Won TB et al. Nasal polyps: An independent risk factor for bronchial hyperresponsiveness in patients with allergic rhinitis. Am J Rhinol Allergy 2010;24:359-63.

Alles R, Parikh A, Hawk L, Darby Y, Romero JN, Scadding G. The prevalence of atopic disorders in children with chronic otitis media with effusion. Pediatr Allergy Immunol 2001;12:102-6.

Bachert C, van Cauwenberge P, Khaltaev N. Allergic rhinitis and its impact on asthma. In collaboration with the World Health Organization. Executive summary of the workshop report. 7-10 December 1999, Geneva, Switzerland. Allergy 2002;57:841-55.

Baraniuk JN. Pathogenesis of allergic rhinitis. J Allergy Clin Immunol 1997;99:S763-72. 
Bhattacharyya N, Vyas DK, Fechner FP, Gliklich RE, Metson R. Tissue eosinophilia in chronic sinusitis: quantification techniques. Arch Otolaryngol Head Neck Surg 2001;127:1102-5.

Bousquet J, Van Cauwenberge P, Khaltaev N. Allergic rhinitis and its impact on asthma. J Allergy Clin Immunol 2001;108:S147-334.

Bousquet J, Vignola AM, Demoly P. Links between rhinitis and asthma. Allergy 2003;58:691706.

Bousquet J, Neukirch F, Bousquet PJ et al. Severity and impairment of allergic rhinitis in patients consulting in primary care. J Allergy Clin Immunol 2006;117:158-62.

Bousquet J, Khaltaev N, Cruz AA et al. Allergic Rhinitis and its Impact on Asthma (ARIA) 2008 update (in collaboration with the World Health Organization, GA(2)LEN and AllerGen). Allergy 2008;63 Suppl 86:8-160.

Caffarelli C, Savini E, Giordano S, Gianlupi G, Cavagni G. Atopy in children with otitis media with effusion. Clin Exp Allergy 1998;28:591-6.

Canonica GW, Bousquet J, Mullol J, Scadding GK, Virchow JC. A survey of the burden of allergic rhinitis in Europe. Allergy 2007;62 Suppl 85:17-25.

Cengel S, Akyol MU. The role of topical nasal steroids in the treatment of children with otitis media with effusion and/or adenoid hypertrophy. Int $J$ Pediatr Otorhinolaryngol 2006;70:639-45.

Choi SH, Yoo Y, Yu J, Rhee CS, Min YG, Koh YY. Bronchial hyperresponsiveness in young children with allergic rhinitis and its risk factors. Allergy 2007;62:1051-6.

Christodoulopoulos P, Cameron L, Durham S, Hamid Q. Molecular pathology of allergic disease. II: Upper airway disease. J Allergy Clin Immunol 2000;105:211-23.

Ciprandi G, Cirillo I, Pistorio A, La Grutta S, Tosca M. Impact of allergic rhinitis on asthma: effects on bronchodilation testing. Ann Allergy Asthma Immunol 2008;101:42-6.

Conner BL, Roach ES, Laster W, Georgitis JW. Magnetic resonance imaging of the paranasal sinuses: frequency and type of abnormalities. Ann Allergy 1989;62:457-60.

Crystal-Peters J, Neslusan C, Crown WH, Torres A. Treating allergic rhinitis in patients with comorbid asthma: the risk of asthma-related hospitalizations and emergency department visits. J Allergy Clin Immunol 2002;109:57-62.

Doyle WJ, Friedman R, Fireman P, Bluestone CD. Eustachian tube obstruction after provocative nasal antigen challenge. Arch Otolaryngol 1984;110:508-11.

Ebert CS, Jr., Rose AS, Blanks DA et al. Immune modulatory oligonucleotides in prevention of nasal allergen-induced Eustachian tube dysfunction in rats. Otolaryngol Head Neck Surg 2007;137:250-5.

Fireman P. Otitis media and nasal disease: a role for allergy. J Allergy Clin Immunol 1988;82:917-26.

Gaugris S, Sazonov-Kocevar V, Thomas M. Burden of concomitant allergic rhinitis in adults with asthma. J Asthma 2006;43:1-7.

Griffin GH, Flynn C, Bailey RE, Schultz JK. Antihistamines and/or decongestants for otitis media with effusion (OME) in children. Cochrane Database Syst Rev 2006:CD003423.

Guerra S, Sherrill DL, Martinez FD, Barbee RA. Rhinitis as an independent risk factor for adult-onset asthma. J Allergy Clin Immunol 2002;109:419-25. 
Gwaltney JM, Jr., Jones JG, Kennedy DW. Medical management of sinusitis: educational goals and management guidelines. The International Conference on sinus Disease. Ann Otol Rhinol Laryngol Suppl 1995;167:22-30.

Hurst DS. Association of otitis media with effusion and allergy as demonstrated by intradermal skin testing and eosinophil cationic protein levels in both middle ear effusions and mucosal biopsies. Laryngoscope 1996;106:1128-37.

Jauregui I, Mullol J, Davila I et al. Allergic rhinitis and school performance. J Investig Allergol Clin Immunol 2009;19 Suppl 1:32-9.

Kaufman J, Chen JC, Wright GW. The effect of trigeminal resection on reflex bronchoconstriction after nasal and nasopharyngeal irritation in man. Am Rev Respir Dis 1970;101:768-9.

Kennedy DW. Prognostic factors, outcomes and staging in ethmoid sinus surgery. Laryngoscope 1992;102:1-18.

Lamb CE, Ratner PH, Johnson CE et al. Economic impact of workplace productivity losses due to allergic rhinitis compared with select medical conditions in the United States from an employer perspective. Curr Med Res Opin 2006;22:1203-10.

Leger D, Annesi-Maesano I, Carat F et al. Allergic rhinitis and its consequences on quality of sleep: An unexplored area. Arch Intern Med 2006;166:1744-8.

Leynaert B, Neukirch F, Demoly P, Bousquet J. Epidemiologic evidence for asthma and rhinitis comorbidity. J Allergy Clin Immunol 2000;106:S201-5.

Luong A, Roland PS. The link between allergic rhinitis and chronic otitis media with effusion in atopic patients. Otolaryngol Clin North Am 2008;41:311-23, vi.

Marshall PS, O'Hara C, Steinberg P. Effects of seasonal allergic rhinitis on selected cognitive abilities. Ann Allergy Asthma Immunol 2000;84:403-10.

McColley SA, Carroll JL, Curtis S, Loughlin GM, Sampson HA. High prevalence of allergic sensitization in children with habitual snoring and obstructive sleep apnea. Chest 1997;111:170-3.

Meltzer EO. Quality of life in adults and children with allergic rhinitis. J Allergy Clin Immunol 2001;108:S45-53.

Meltzer EO. Introduction: Stuffy is also related to Sleepy and Grumpy--the link between rhinitis and sleep-disordered breathing. J Allergy Clin Immunol 2004;114:S133-4.

Meltzer EO. The relationships of rhinitis and asthma. Allergy Asthma Proc 2005;26:336-40.

Nguyen LH, Manoukian JJ, Sobol SE et al. Similar allergic inflammation in the middle ear and the upper airway: evidence linking otitis media with effusion to the united airways concept. J Allergy Clin Immunol 2004;114:1110-5.

O'Connor RD, Ort H, Leong AB, Cook DA, Street D, Hamburger RN. Tympanometric changes following nasal antigen challenge in children with allergic rhinitis. Ann Allergy 1984;53:468-71.

Osur SL, Volovitz B, Dickson S, Enck DC, Bernstein JM. Eustachian tube dysfunction in children with ragweed hayfever during natural pollen exposure. Allergy Proc 1989;10:133-9.

Pelikan Z, Pelikan-Filipek M. Role of nasal allergy in chronic maxillary sinusitis--diagnostic value of nasal challenge with allergen. J Allergy Clin Immunol 1990;86:484-91. 
Rosenfeld RM, Mandel EM, Bluestone CD. Systemic steroids for otitis media with effusion in children. Arch Otolaryngol Head Neck Surg 1991;117:984-9.

Savolainen S. Allergy in patients with acute maxillary sinusitis. Allergy 1989;44:116-22.

Scharf MB, Cohen AP. Diagnostic and treatment implications of nasal obstruction in snoring and obstructive sleep apnea. Ann Allergy Asthma Immunol 1998;81:279-87; quiz 8790.

Schatz M. A survey of the burden of allergic rhinitis in the USA. Allergy 2007;62 Suppl 85:916.

Settipane RJ, Hagy GW, Settipane GA. Long-term risk factors for developing asthma and allergic rhinitis: a 23-year follow-up study of college students. Allergy Proc 1994;15:21-5.

Shaaban R, Zureik M, Soussan D et al. Rhinitis and onset of asthma: a longitudinal population-based study. Lancet 2008;372:1049-57.

Shekelle P, Takata G, Chan LS et al. Diagnosis, natural history, and late effects of otitis media with effusion. Evid Rep Technol Assess (Summ) 2002:1-5.

Slavin RG. Complications of allergic rhinitis: implications for sinusitis and asthma. J Allergy Clin Immunol 1998;101:S357-60.

Sobol SE, Taha R, Schloss MD et al. T(H)2 cytokine expression in atopic children with otitis media with effusion. J Allergy Clin Immunol 2002;110:125-30.

Spector SL. Overview of comorbid associations of allergic rhinitis. J Allergy Clin Immunol 1997;99:S773-80.

Thomas CL, Simpson S, Butler CC, van der Voort JH. Oral or topical nasal steroids for hearing loss associated with otitis media with effusion in children. Cochrane Database Syst Rev 2006;3:CD001935.

Tomonaga K, Kurono Y, Mogi G. The role of nasal allergy in otitis media with effusion. A clinical study. Acta Otolaryngol Suppl 1988;458:41-7.

Tos M. Epidemiology and natural history of secretory otitis. Am J Otol 1984;5:459-62.

Tracy JM, Demain JG, Hoffman KM, Goetz DW. Intranasal beclomethasone as an adjunct to treatment of chronic middle ear effusion. Ann Allergy Asthma Immunol 1998;80:198206.

Vuurman EF, van Veggel LM, Uiterwijk MM, Leutner D, O'Hanlon JF. Seasonal allergic rhinitis and antihistamine effects on children's learning. Ann Allergy 1993;71: 121-6.

Walker S, Khan-Wasti S, Fletcher M, Cullinan P, Harris J, Sheikh A. Seasonal allergic rhinitis is associated with a detrimental effect on examination performance in United Kingdom teenagers: case-control study. J Allergy Clin Immunol 2007;120:381-7.

Watson WT, Becker $\mathrm{AB}$, Simons FE. Treatment of allergic rhinitis with intranasal corticosteroids in patients with mild asthma: effect on lower airway responsiveness. J Allergy Clin Immunol 1993;91:97-101.

Williamson IG, Dunleavey J, Bain J, Robinson D. The natural history of otitis media with effusion--a three-year study of the incidence and prevalence of abnormal tympanograms in four South West Hampshire infant and first schools. J Laryngol Otol 1994;108:930-4. 
Young T, Finn L, Kim H. Nasal obstruction as a risk factor for sleep-disordered breathing. The University of Wisconsin Sleep and Respiratory Research Group. J Allergy Clin Immunol 1997;99:S757-62. 


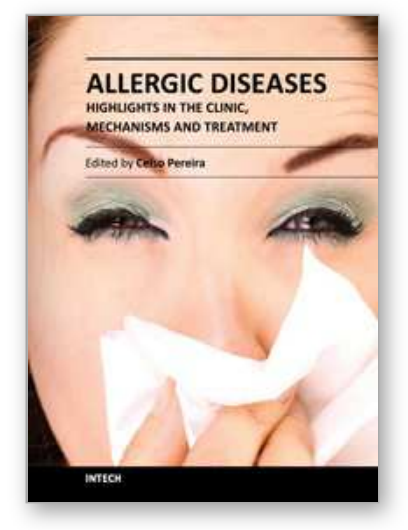

\author{
Allergic Diseases - Highlights in the Clinic, Mechanisms and \\ Treatment \\ Edited by Prof. Celso Pereira
}

ISBN 978-953-51-0227-4

Hard cover, 554 pages

Publisher InTech

Published online 14, March, 2012

Published in print edition March, 2012

The present Edition "Allergic diseases - highlights in the clinic, mechanisms and treatment" aims to present some recent aspects related to one of the most prevalent daily clinical expression disease. The effort of a group of outstanding experts from many countries reflects a set of scientific studies very promising for a better clinical care and also to the treatment and control of the allergy. This book provides a valuable reference text in several topics of the clinical allergy and basic issues related to the immune system response. The inflammatory reaction understanding in allergic disease is clearly evidenced, as well as new strategies for further researches.

\title{
How to reference
}

In order to correctly reference this scholarly work, feel free to copy and paste the following:

Doo Hee Han and Chae-Seo Rhee (2012). Comorbidities of Allergic Rhinitis, Allergic Diseases - Highlights in the Clinic, Mechanisms and Treatment, Prof. Celso Pereira (Ed.), ISBN: 978-953-51-0227-4, InTech, Available from: http://www.intechopen.com/books/allergic-diseases-highlights-in-the-clinic-mechanisms-andtreatment/co-morbidities-of-allergic-rhinitis

\section{INTECH}

open science | open minds

\section{InTech Europe}

University Campus STeP Ri

Slavka Krautzeka 83/A

51000 Rijeka, Croatia

Phone: +385 (51) 770447

Fax: +385 (51) 686166

www.intechopen.com

\section{InTech China}

Unit 405, Office Block, Hotel Equatorial Shanghai

No.65, Yan An Road (West), Shanghai, 200040, China

中国上海市延安西路65号上海国际贵都大饭店办公楼 405 单元

Phone: +86-21-62489820

Fax: $+86-21-62489821$ 
(C) 2012 The Author(s). Licensee IntechOpen. This is an open access article distributed under the terms of the Creative Commons Attribution 3.0 License, which permits unrestricted use, distribution, and reproduction in any medium, provided the original work is properly cited. 